
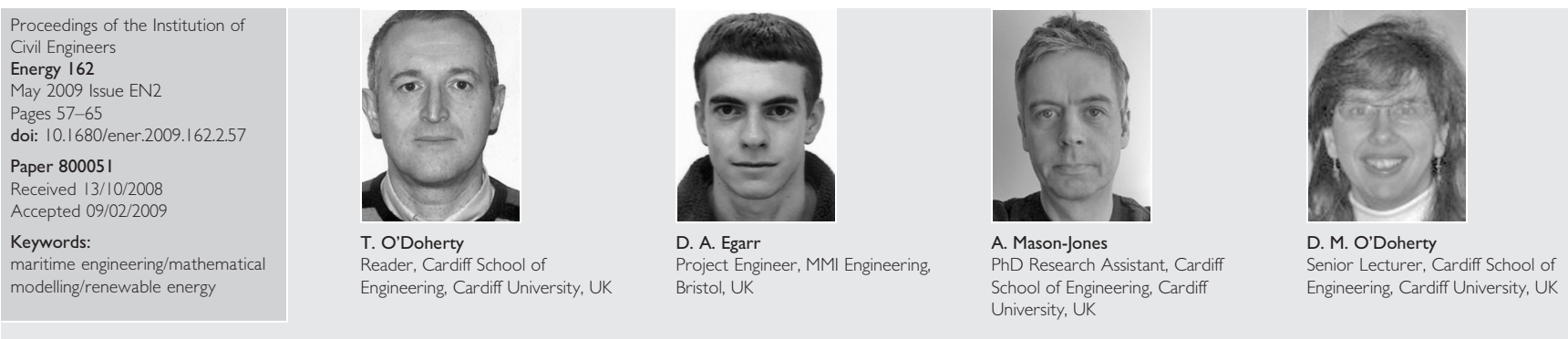

\title{
An assessment of axial loading on a five-turbine array
}

T. O’Doherty PhD, CEng, FIMechE, MEl, D. A. Egarr MEng, PhD, A. Mason-Jones MSc and D. M. O'Doherty PhD, CEng, MIMechE, MEI

\begin{abstract}
A structure that supports five turbines with a power coefficient of 0.40 (efficiency of $68 \%$ ) has been studied using computational fluid dynamics to assess the power extracted and the flow field in a $3 \mathrm{~m} / \mathrm{s}$ (6 knot) tidal flow. Peak axial sliding forces were assessed to determine anchorage requirements. While it is recognised that the turbines will most likely be positioned in relatively deep water in areas of steep tidal velocity gradients, this study considers the worst-case scenario for the axial sliding forces - that is, a uniform $3 \mathrm{~m} / \mathrm{s}$ tidal velocity profile. The analysis shows that the fluid velocity increases around the structure, which could possibly be used advantageously in the placing of multiple turbine arrays. There is minimal interference between the wakes of the individual turbines, but there is interference between the wakes of some turbines and the bracing that forms part of the structure. The axial sliding force was found to be highest when the frame apex is head into the flow, and it is estimated that the coefficient of friction between the seabed and the array frame must be lower than $\mathbf{0 . 4 3}$ for sliding to occur with no additional ballast or anchorage.
\end{abstract}

$\begin{array}{ll}\text { NOTATION } \\ A & \text { cross-sectional area of the turbine, area vector }\left(\mathrm{m}^{2}\right) \\ \boldsymbol{F} & \text { force }(\mathrm{N}) \\ \boldsymbol{g} & \text { acceleration due to gravity }\left(\mathrm{m} / \mathrm{s}^{2}\right) \\ m_{\mathrm{f}} & \text { mass of displaced fluid }(\mathrm{kg}) \\ m_{\mathrm{s}} & \text { mass of structure }(\mathrm{kg}) \\ N & \text { total number of faces } \\ n & \text { face number } \\ \boldsymbol{P} & \text { static pressure acting on the face or element }\left(\mathrm{N} / \mathrm{m}^{2}\right) \\ r & \text { distance }(\mathrm{m}) \\ \boldsymbol{T} & \text { torque }(\mathrm{Nm}) \\ \boldsymbol{V} & \text { free stream velocity }(\mathrm{m} / \mathrm{s}) \\ \mu & \text { coefficient of friction } \\ \rho & \text { fluid density }\left(\mathrm{kg} / \mathrm{m}^{3}\right) \\ \boldsymbol{\omega} & \text { angular velocity of turbine }(\mathrm{rad} / \mathrm{s})\end{array}$

\section{INTRODUCTION}

Tidal stream resources have the potential to generate $15.6 \mathrm{TWh}$, which is approximately $4 \%$ of the annual UK electricity demand. However, this figure is slightly reduced by the 'significant impact factor' (SIF) as presented by Black and Veatch. ${ }^{1}$ The resulting figure of $12 \mathrm{TWh} /$ year represents the UK tidal stream resource that could be economically exploited if the technology were to be developed and deployed.

To date, UK tidal stream technology has resulted in a number of installed full-scale devices. Marine Current Turbines' (MCT's) Seaflow, the world's first offshore tidal stream turbine, was built into the seabed $1.5 \mathrm{~km}$ offshore from Lynmouth, Devon, UK. It comprises an $11 \mathrm{~m}$ diameter twin-bladed turbine and is capable of producing $300 \mathrm{~kW}$ of electricity at a tidal flow of about $2 \cdot 8 \mathrm{~m} / \mathrm{s}$ (5.5 knots). ${ }^{2}$ MCT also developed the more recent $1 \cdot 2 \mathrm{MW}$ SeaGen project at Strangford Lough off the coast of Northern Ireland, which will supply electricity to up to 1000 homes. ${ }^{3,4}$ The company has also commenced studies for an array of turbines producing 10.5 MW situated in the fastflowing waters within The Skerries off the coast of Anglesey in North Wales. ${ }^{5}$

The clear advantage of tidal stream turbines is that they can be sized to suit the requirements of the local environment - that is, coastal restrictions, tidal flow, tidal range, seabed topography, and so on - and can be placed in either individual or 'farm' configurations. As such, no large (as compared with tidal impoundment schemes) civil engineering works are required; the method is therefore less disruptive to wildlife, marine activity and possibly the coastline, and does not present a significant barrier to water transport. It has been stated that the ideal location for a tidal stream turbine is within $1 \mathrm{~km}$ of the shoreline at a depth of $20-30 \mathrm{~m}^{6}{ }^{6}$ The ideal tidal speed is 2-3 m/s (about 4-6 knots) as higher speeds can lead to blade loading problems. ${ }^{7}$

A recent survey on the extractable tidal resource distribution by depth suggests that $63 \%$ of the total resource is at depths greater than $40 \mathrm{~m}$ with a mean spring peak velocity $\left(\boldsymbol{V}_{\mathrm{msp}}\right)$ of between 2.5 and $5.5 \mathrm{~m} / \mathrm{s}$ and above. Although more challenging to deploy and maintain, there is considerable resource at depths greater than $40 \mathrm{~m}$ - estimated to be $28 \%$ with a $\boldsymbol{V}_{\text {msp }}$ of $5.5 \mathrm{~m} / \mathrm{s}$ and above. Between 30 and $40 \mathrm{~m}$ depth, the $\boldsymbol{V}_{\text {msp }}$ ranges between 2.5 and $3.5 \mathrm{~m} / \mathrm{s}$, with an extractable resource of $18 \% .{ }^{1}$ It is within this latter velocity and depth range that tidal turbines such as those already mentioned are initially being developed. It is unlikely that attention will be given to depths less than $25 \mathrm{~m}$ as there the peak resource is only around $3 \cdot 4 \%$. 
A report on resource availability by The Carbon Trust ${ }^{8}$ splits the UK into five resource regions: the Channel Islands, Northern Ireland, the North West, Pentland and the South West. The total energy yield from each of these sites is $3 \cdot 017,1 \cdot 045,2 \cdot 033$, $8 \cdot 120$ and $1.229 \mathrm{TWh} /$ year, respectively. The South West region includes four locations within the Bristol Channel, namely Barry, Foreland Point and South and North Lundy. The total energy yield from these four locations is $712 \mathrm{GWh} / y e a r$, representing around 58\% of the total energy yield from the South West region and around 5\% of the total UK resource, making the Bristol Channel a viable energy source.

Using the computational fluid dynamics (CFD) package Fluent, Egarr et al. $^{9}$ analysed the power predictions and flow characteristics of a four-blade turbine for which reasonable validation was achieved. Further work then focused on threeblade turbines in isolation, for which power predictions were made at a number of tidal velocities between 0.51 and $3.09 \mathrm{~m} / \mathrm{s}$ (1-6 knots). ${ }^{9}$ The horizontal, or axial sliding, force on the turbine was also investigated and found to peak at the freewheeling velocity. The work has been developed further (as detailed in this paper) using the same three-blade $10 \mathrm{~m}$ diameter turbine design, which has a power coefficient $C_{\mathrm{p}}$ of $0 \cdot 40$ (or an efficiency of $\sim 68 \%$ ), to study power predictions and the peak axial sliding force of the turbine in isolation, a turbine and stanchion combination and a five-turbine array as shown in Figure 1. To date, most tidal turbine work has utilised one or two turbines mounted on a single stanchion; this work indicates the effects of interlinking a series of turbines.

The array is an equilateral frame, each side $56 \mathrm{~m}$ long. The structure rests on the seabed supported by a stanchion at each corner, $3.4 \mathrm{~m}$ in diameter and $18 \mathrm{~m}$ high. If the mass of each component shown in Figure 1 is assumed to be half that of a solid component and the average density equivalent to steel, approximately $8000 \mathrm{~kg} / \mathrm{m}^{3}$, the overall mass of the structure would be of the order of $2200 \mathrm{t}$. Hence, part of the study is to determine the total peak sliding force on the frame and to assess whether extra ballast or support would be required. If not, this array may offer a less expensive option to piling turbines into the seabed. Bracing, $0.6 \mathrm{~m}$ in diameter, connects each stanchion as shown. The total height of the frame is approximately $40 \mathrm{~m}$ due to three pieces of bracing extending from the three corners

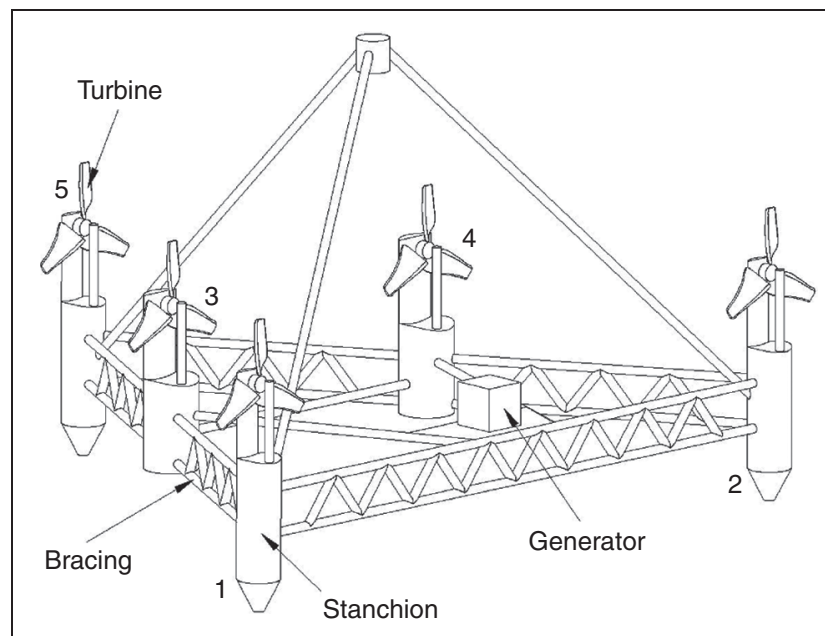

Figure I. The five-turbine array of the array to meet a cylindrical section used to lower the array into the sea. A generator, sealed in a casing, is positioned on the frame as shown in Figure 1. Each turbine, $10 \mathrm{~m}$ in diameter, was modelled with a section of the stanchion at the front and rear, with the front support of each stanchion being a slender cylindrical member, as shown in Figure 1. It is assumed that each stanchion will allow the turbine to swivel, to align with the direction of flow. It is clear that as the tide turns, some turbines will be in the shadow of another turbine, but during this stage of the tide the power extraction would obviously be minimal. In this study, the performance of each turbine is analysed with the flow approaching the frame with the apex head and tail into the flow. The apex is referred to as the position of turbine 5 as depicted in Figure 1.

\section{THEORY}

\section{I. Turbine efficiency}

The maximum theoretical efficiency of a frictionless turbine was predicted by Betz in 1920 by considering a turbine in a stream tube. ${ }^{10}$ Performing a force balance on the turbine and applying the incompressible form of Bernoulli's equation, it can be shown that the maximum power that can be extracted by the turbine is

\begin{tabular}{|l|l|}
\hline I & $\boldsymbol{P}_{\text {max }}=\frac{8}{27} \rho A \boldsymbol{V}^{3}$ \\
\hline
\end{tabular}

and the velocity through the turbine at $\boldsymbol{P}_{\max }$ is $2 \boldsymbol{V} / 3$. A detailed derivation is given by White. ${ }^{11}$

The available power to a turbine is determined by considering the kinetic energy in a stream tube with a diameter identical to the turbine, thus

\begin{tabular}{|l|l|}
\hline 2 & $\boldsymbol{P}_{\text {available }}=\frac{1}{2} \rho A \boldsymbol{V}^{3}$ \\
\hline
\end{tabular}

Thus, the maximum possible efficiency, known as the Betz limit, ${ }^{10}$ is $59 \cdot 3 \%$ where the efficiency is given by

$3=100 \frac{\boldsymbol{P}_{\text {extracted }}}{\boldsymbol{P}_{\text {available }}}$

\subsection{Determination of turbine power using numerical methods}

A real turbine is not frictionless, as assumed in the derivation of the Betz limit, thus the force acting on the turbine $\boldsymbol{F}_{\mathrm{t}}$ is made up of the shear force on the turbine blades $\boldsymbol{F}_{\mathrm{s}}$ and the force due to the static pressure $\boldsymbol{F}_{\mathrm{p}}$

\begin{tabular}{|l|l|}
\hline 4 & $\boldsymbol{F}_{\mathrm{t}}=\boldsymbol{F}_{\mathrm{s}}+\boldsymbol{F}_{\mathrm{p}}$ \\
\hline
\end{tabular}

To calculate the force on a member, for example turbine or stanchion, that has been divided into finite faces, the forces in the $x, y$ and $z$ components must be considered. The force due to the static pressure is given by the product of the static pressure and the area vector of the face, hence, in the $x$ component

\begin{tabular}{|l|l|}
\hline 5 & $\boldsymbol{F}_{\mathrm{p} x}=\boldsymbol{P} A_{x}$ \\
\hline
\end{tabular}


When calculating the power extracted by a turbine, torque is required only for the components of the forces in which the plane of the turbine lies. Hence, if the turbine axis is in the $z$ direction, then only the forces in the $x$ and $y$ components are required. For simplicity, consider the case for the origin of axis of rotation of the turbine at $(0,0,0)$. Then the total torque acting on the turbine is the summation of the torque acting on each face which is given by the cross-product of the distance and force vectors; that is

\begin{tabular}{|l|l|}
\hline 6 & $\boldsymbol{T}=\sum_{n=1}^{n=N}\left[r_{x} \boldsymbol{F}_{y}-r_{y} \boldsymbol{F}_{x}\right]$ \\
\hline
\end{tabular}

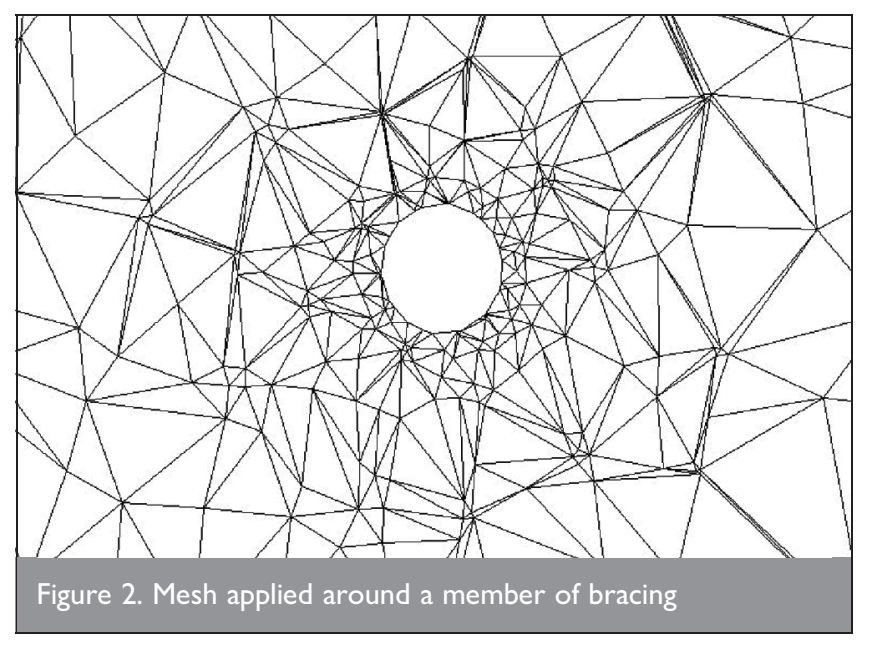

The power being extracted by the turbine is then given by

\begin{tabular}{|l|c|}
\hline 7 & $P_{\text {extracted }}=T \omega$ \\
\hline
\end{tabular}

\subsection{Frame forces}

If gravity is considered to be acting on the frame in the positive $y$ component, then the forces that will result in sliding are in the $x$ and $z$ components. Hence, the resultant sliding force is given by

$$
\boldsymbol{F}_{\text {sliding }}=\left(\boldsymbol{F}_{x}^{2}+\boldsymbol{F}_{z}^{2}\right)^{1 / 2}
$$

The frame will therefore resist sliding when

\begin{tabular}{|l|l|}
\hline 9 & $\mu \geqslant \frac{\boldsymbol{F}_{\text {sliding }}}{\left(m_{\mathrm{s}}-m_{\mathrm{f}}\right) \boldsymbol{g}+\boldsymbol{F}_{y}}$ \\
\hline
\end{tabular}

\section{GRID SET-UP}

To determine the force on each component of the five-turbine array, each member shown in Figure 1 was incorporated into the model. Due to the complex geometry, a purely tetrahedral grid was used. A cylindrical region (diameter $16 \mathrm{~m}$ and length $6 \mathrm{~m}$ ) around each turbine was created and incorporated approximately 960000 cells so that adequate resolution was present to accurately capture the pressure distribution upstream and downstream of the turbine, particularly on the faces of the turbine blades. A sufficient resolution was also required around each member of bracing such that each was modelled as a cylindrical member and not, for example, a pentagon which would have a higher drag force associated with it. This is because each face that forms part of the member is formed from a set of straight edges, which creates a 'flat' face. Figure 2 shows a typical mesh applied around a member of bracing used in the CFD model and demonstrates that a sufficiently fine mesh was used to capture the shape.

The topology of the region in which a tidal turbine can be located varies from site to site. For assessing the force on the turbine array and for studying the flow field, it was felt that a domain the shape of a rectangular channel with a flat bed would be sufficient, with a free surface represented by a frictionless wall. Initially, models were created with different widths in order to select a channel width that minimised boundary effects but which was sufficiently low to keep the grid

size as small as possible. The chosen channel width was $270 \mathrm{~m}$, with the array positioned approximately $60 \mathrm{~m}$ downstream from a velocity inlet.

In using an adequate number of cells around the bracing and turbines to accurately predict the forces and power extracted by each turbine, the total number of cells used to model the sea was just over three million. The aspect ratio of any cell did not exceed $0 \cdot 87$. The size of the grid was unavoidable despite using custom sizing functions in parts of the model to increase the rate of growth of cells away from certain members and hence decrease the total number of cells in the model. With such a computationally expensive grid, the model had to be solved using parallel processing.

The sides of the channel were specified as frictionless walls to reduce boundary layer effects. The inlet velocity profile was assumed constant at $3.09 \mathrm{~m} / \mathrm{s}$ (6 knots) across the entire surface and a pressure outlet for the outflow. Mason-Jones et al. ${ }^{12,13}$ discuss measured velocity profiles made in the Bristol Channel using a series of acoustic Doppler current profiler (ADCP) surveys, three nautical miles south of Stout Point, South Wales. Examples of the profiles (see Figure 3) clearly show a steep velocity gradient down the water column. The constant velocity profile is, however, justified even recognising the potential for a steep velocity gradient, since the worst-case scenario for sliding forces has been considered using the peak velocity.

The rotation of each turbine was modelled using a 'multiple reference frame' approach to give a steady-state solution. Initially, a solution was obtained without the turbines rotating and a tidal velocity set to the required value. The angular velocity of each turbine was then set to be the same for each one and data sets for power, axial force and torque were obtained up to the free-wheeling angular velocity - that is, when the power goes to zero. By varying the angular velocity, the effects of extracting power are modelled and it is possible to determine the angular velocity of the turbines for maximum power extraction.

Using the Reynolds stress model (RSM) as utilised by MasonJones et al., ${ }^{12}$ each complete set of power curves for each condition (apex tail into flow, etc.) required a processing time of typically two weeks of continual run time using parallel processing with four $3 \cdot 2 \mathrm{GHz}$ processors. 


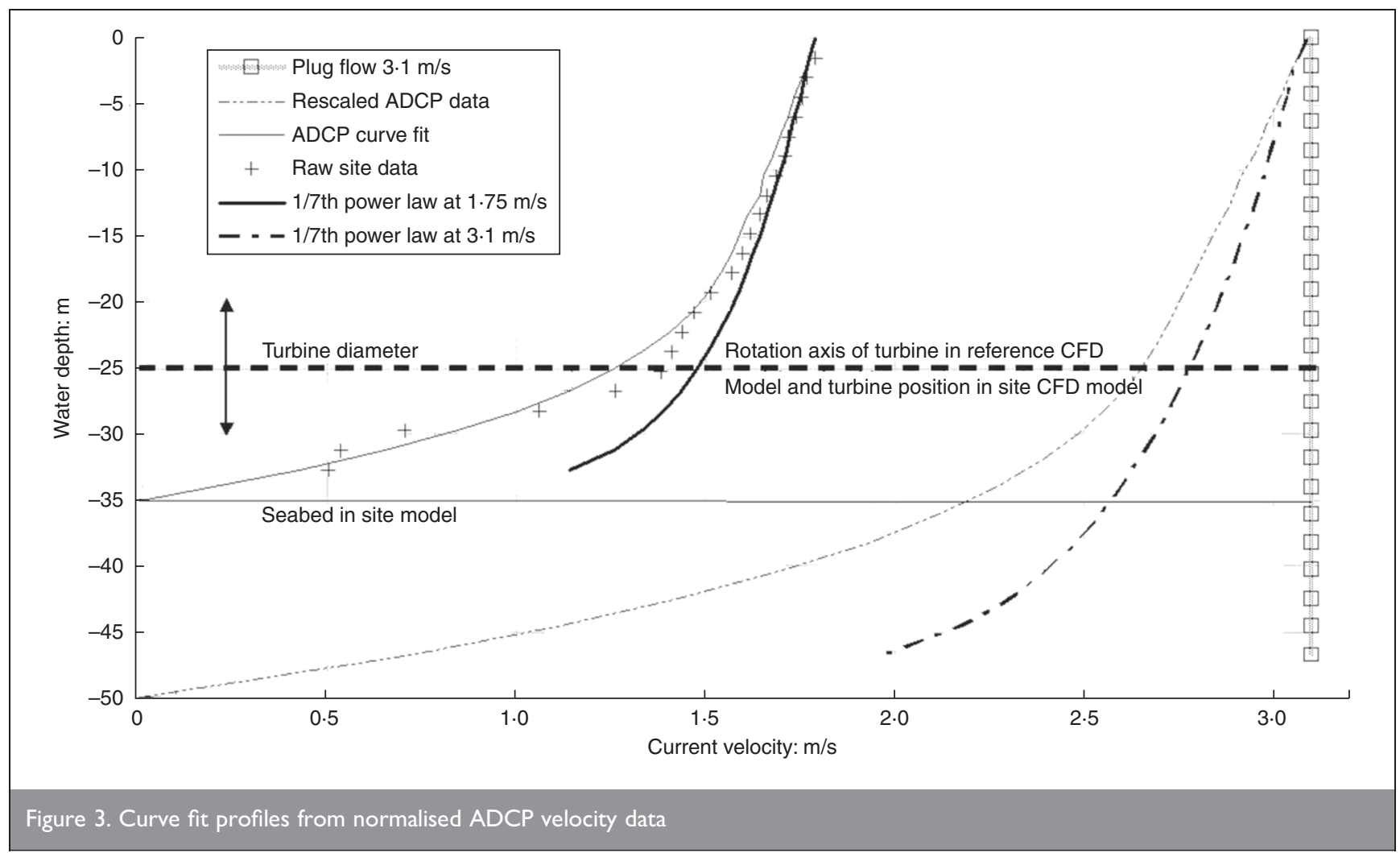

\section{RESULTS}

Figure 4 shows a plan view, horizontally bisecting the turbines, of the flow field at optimum power extraction when the frame apex is tail into the flow. Figure 5 shows a side view - that is, a vertical section through the apex of the array - and Figure 6 shows power curves for each turbine.

Figure 4 shows that there is a localised reduction in velocity in front of turbines 1 and 2 as the flow 'sees' the turbines. The wake from each turbine is being pushed outwards slightly away from the turbine array and there is no interference between the wakes of each turbine. The structure of the turbine array causes a wake, where only $80 \%$ flow recovery has been achieved at $\sim 150 \mathrm{~m}$ downstream. Complete recovery of the fluid is not achieved within the model, but $90 \%$ recovery is estimated at $\sim 450 \mathrm{~m}$ downstream. Due to the reduced velocity downstream of the turbine array, there is an increase of up to $0.5 \mathrm{~m} / \mathrm{s}$ $(\sim 17 \%)$ in the fluid velocity around the structure. Thus, appropriate positioning of numerous turbine arrays could result in a slightly higher available power flux. Figure 5 shows how

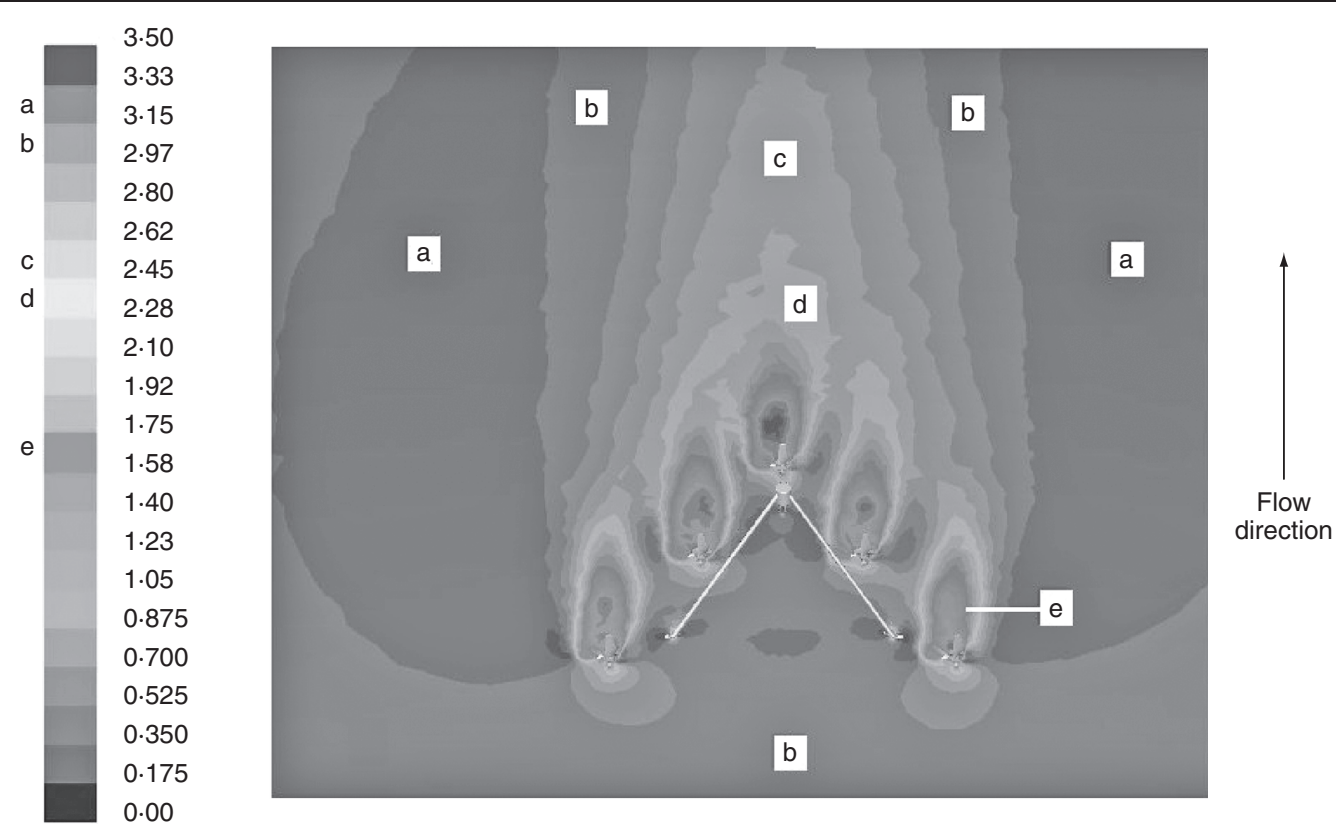

Figure 4. Plan view of flow field around the turbine array with apex tail into the flow 


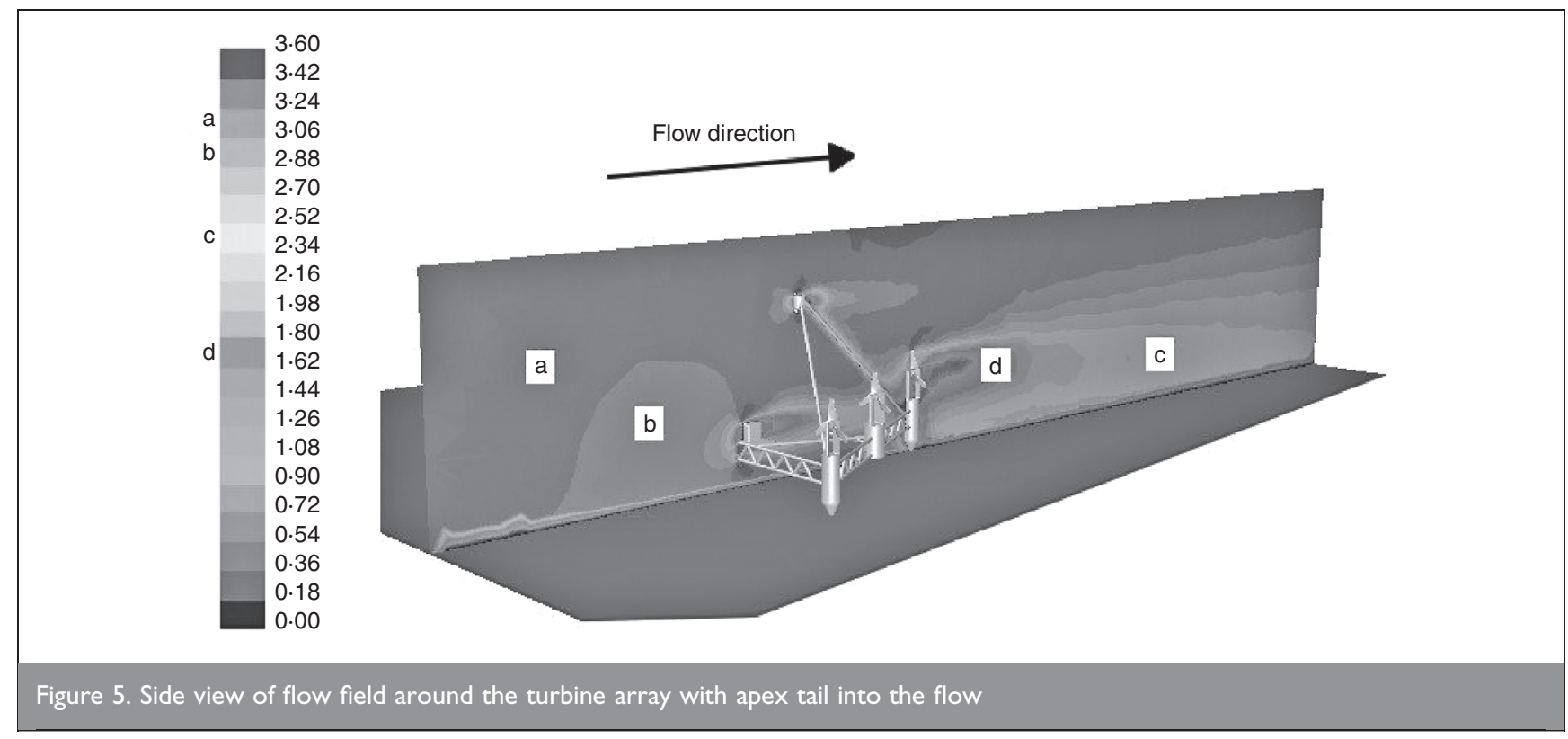

the position of the generator causes a wake downstream. A detailed side view of the wake from turbine 5 is also shown; this wake has tended to push up slightly.

As expected, turbines 1 and 2 extract the most energy from the flow as they are upstream of turbines 3 to 5 where the free stream velocity is lower (see Figure 6). Turbine 5 generates similar power to turbines 3 and 4 and this appears to be attributable to fluid being accelerated between these turbines. Clearly the bracing in front of turbine 5 partly shelters the turbine and this may reduce the available power flux. If there were any vortex shedding from this bracing, turbine 5 may experience a vibration problem.

Figure 7 shows a plan view, horizontally bisecting the turbines, of the flow field at optimum power extraction when the frame apex is head into the flow. Figure 8 shows a side view and Figure 9 shows power curves for each turbine.
Figure 7 shows that the wakes from each turbine are almost parallel with the direction of flow when the frame apex is head into the flow; again, there is no interference between each wake. There is an increase in the fluid velocity each side of the array. Figure 8 shows interference between the region of separation behind turbine 5 and the bracing extending upwards to the section used to lower the array into the estuary. This region of interference could again create a vibration problem in the structure if any time-dependent flow patterns were found to exist within the wake. The same also applies to turbines 3 and 4 and is perhaps better illustrated through an iso-contour of velocity magnitude of $1.3 \mathrm{~m} / \mathrm{s}$ (Figure 10), which shows the wake from the turbines interfering with the bracing. Figure 10 can be compared with Figure 11, where it may be seen that there is no interference between the wakes and the structure. The cause of the wakes in Figures 10 and 11 appears to be attributable to the rear support of the turbine, which, if replaced with a slender support similar to the front, may reduce the size

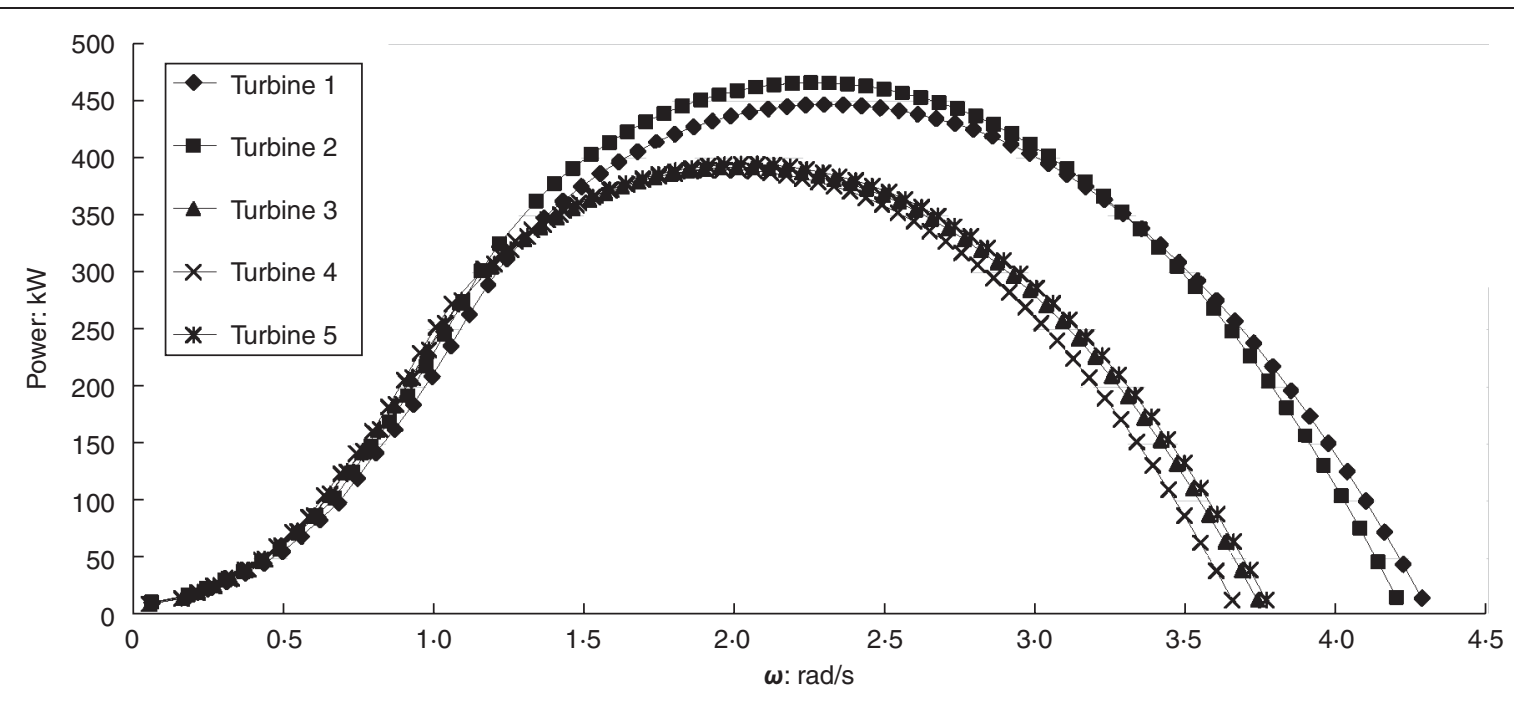

Figure 6. Power curves for each turbine in the array when the frame apex is tail into the flow 


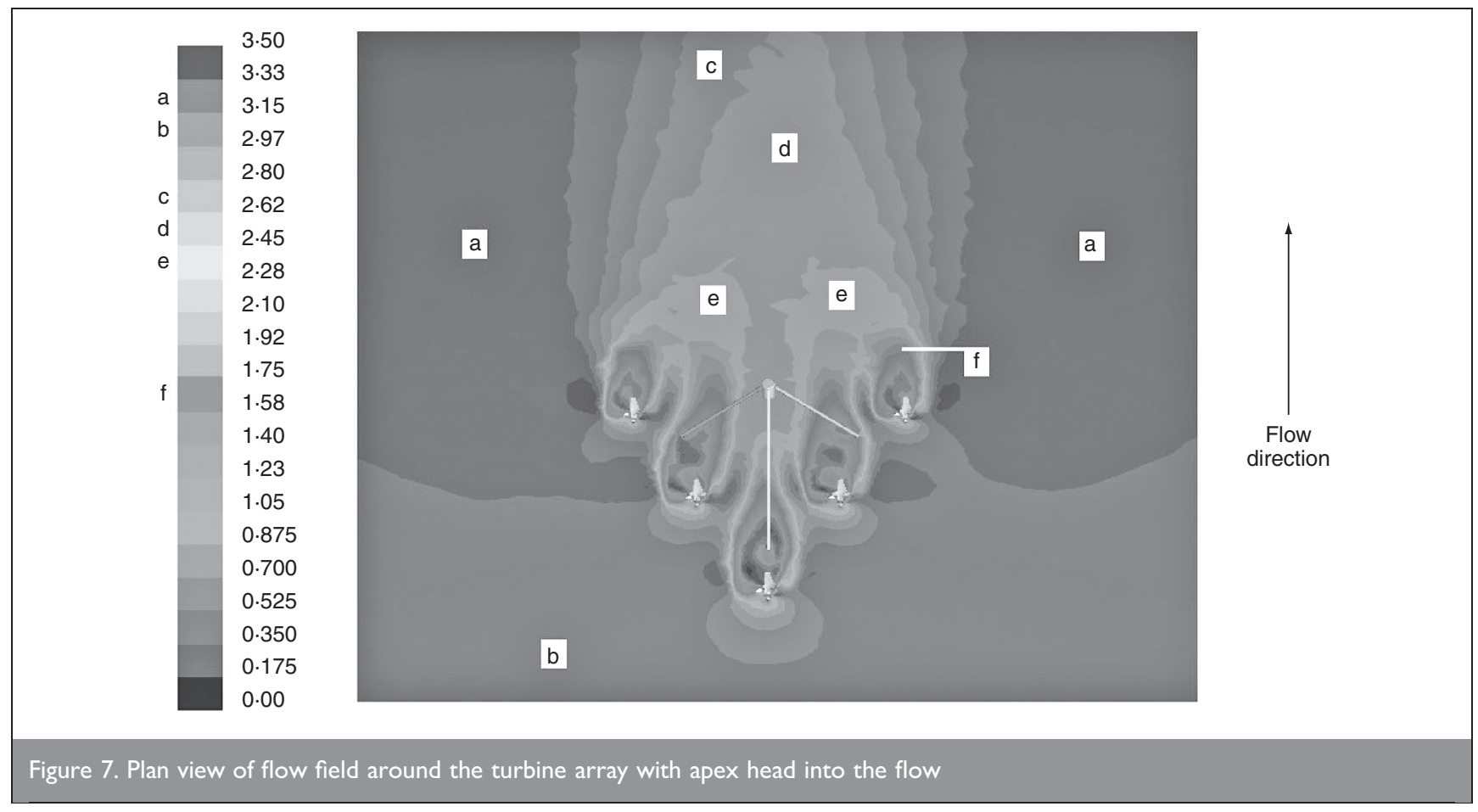

of the wake and also allow more fluid to pass through the turbine, potentially increasing the power extracted.

Figure 9 shows that the position of the generator has again caused a wake downstream. Turbines 1 and 2, although furthest downstream, might be extracting more energy than turbines 3-5 due to the slight increase in fluid velocity at each side of the array and also because there is no disruption to the flow downstream of these turbines.

It is also worth noting that, in all cases, the wake from the array attaches itself to the seabed. This could be the result of the accelerated flow under the turbines causing a reduction in pressure, hence causing the fluid to attach to the surface. Similar effects are seen in fluidic devices utilising the Coanda effect. ${ }^{14}$ This attachment is, however, not seen in turbines that have been modelled in deep water ( $50 \mathrm{~m}$ depth) with the turbine positioned away from the seabed.

Comparing peak power outputs for the two conditions (frame apex tail into the flow and frame apex head into the flow), it can be seen that the peak power output when the apex is head into the flow is around 12\% lower (around $580 \mathrm{~kW}$ compared with $660 \mathrm{~kW}$ for the frame apex tail into the flow). There is also



Figure 8. Side view of flow field around the turbine array with apex head into the flow 


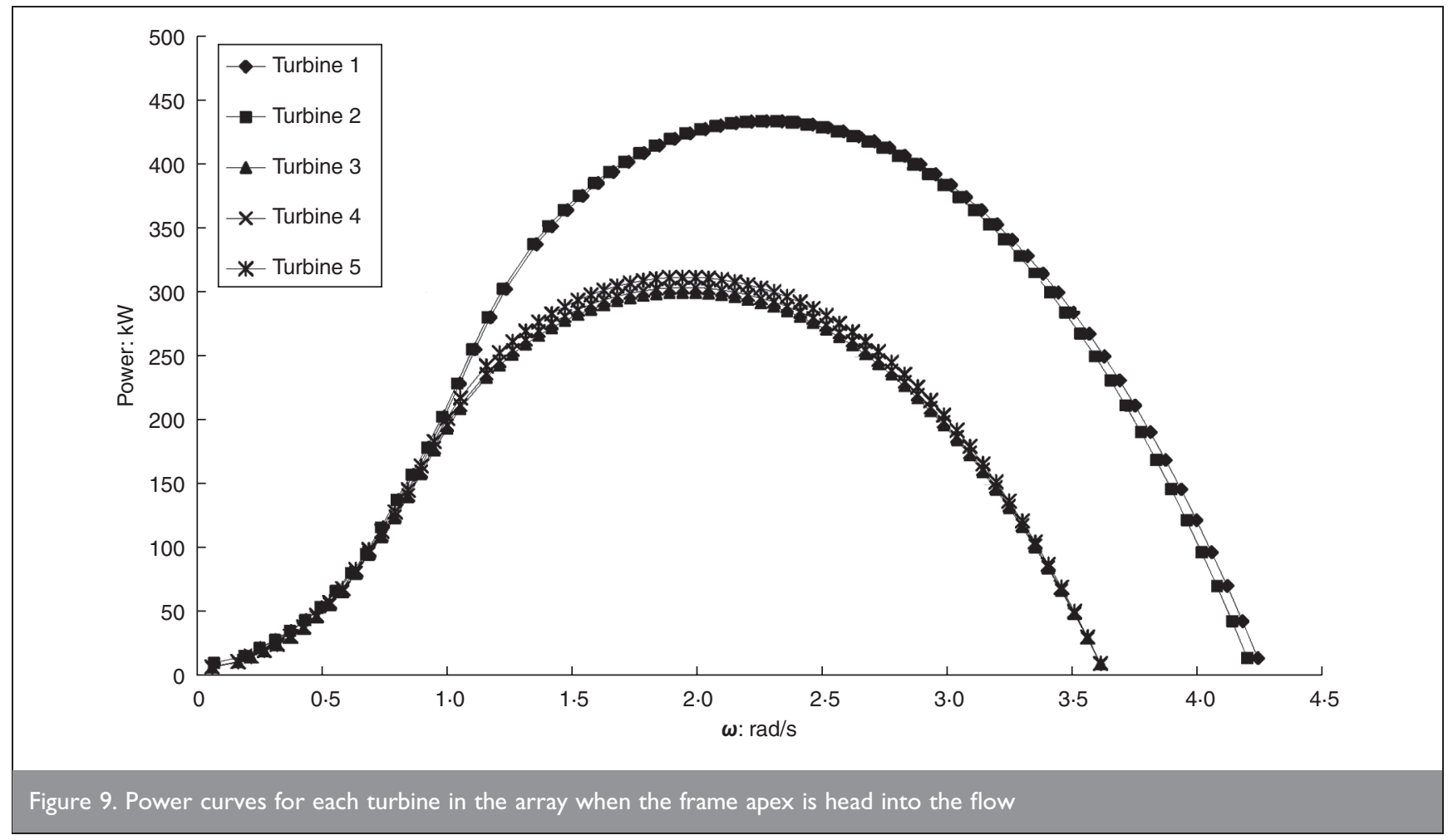

a 10\% drop in array efficiency when compared with the efficiency of five turbines modelled in isolation. However, in this study, the angular velocity of all turbines was set to the same value in order to make direct comparisons. As the velocity of the fluid passing through each turbine is different, the optimum angular velocity of each turbine should be maintained at an appropriate setting to achieve optimum power extraction and a slightly higher output could therefore be expected. ${ }^{9}$

Figure 12 shows that the axial thrust or sliding force at maximum power or when the turbine is free-wheeling is related to the tidal velocity. In both cases the relationship is parabolic. This result is not surprising: Egarr et al. ${ }^{9}$ and Mason-Jones et al. ${ }^{12}$ found that as the angular velocity of a tidal turbine in

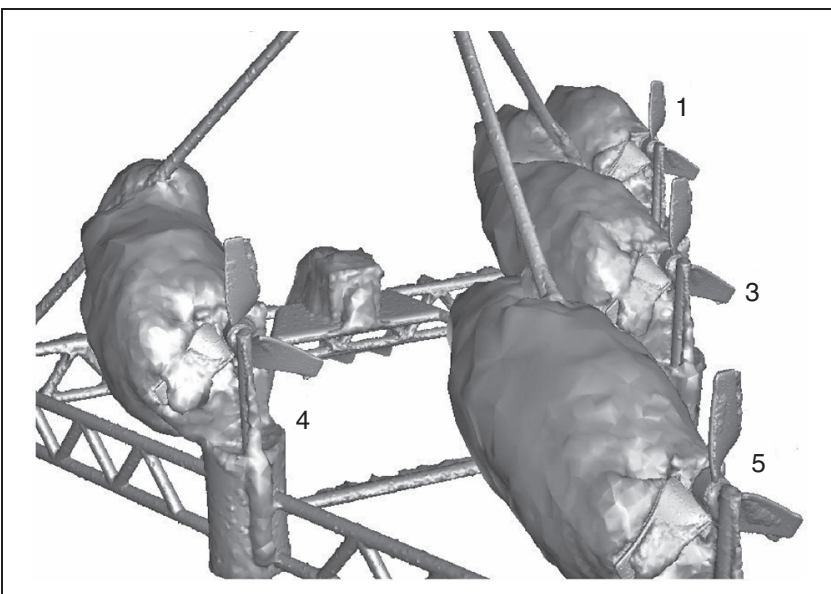

Figure 10. Iso-contours of velocity magnitude $(1.3 \mathrm{~m} / \mathrm{s})$ showing interference between the wake of turbines 4 and 5 with the bracing for the frame apex head into the flow isolation increases, so does the force, which plateaus as the turbine approaches the free-wheeling velocity. This is because when the turbine is free-wheeling, it offers most resistance to the flow. However, the force may continue to increase for an array since the free-wheeling velocity of each turbine occurs at a different angular velocity due to differing free stream fluid velocities approaching each turbine. Thus, the power curves for each case have only been taken as far as the turbine with the lowest free-wheeling velocity allows. The worst case is when the apex of the frame is head into the flow.

Predictions of vertical force as a function of angular velocity of the turbines show that the force changes from acting in an upward to a downward direction as peak power extraction is



Figure II. Iso-contour of velocity magnitude $(1.3 \mathrm{~m} / \mathrm{s})$ showing the wakes of turbines for the frame apex tail into the flow 


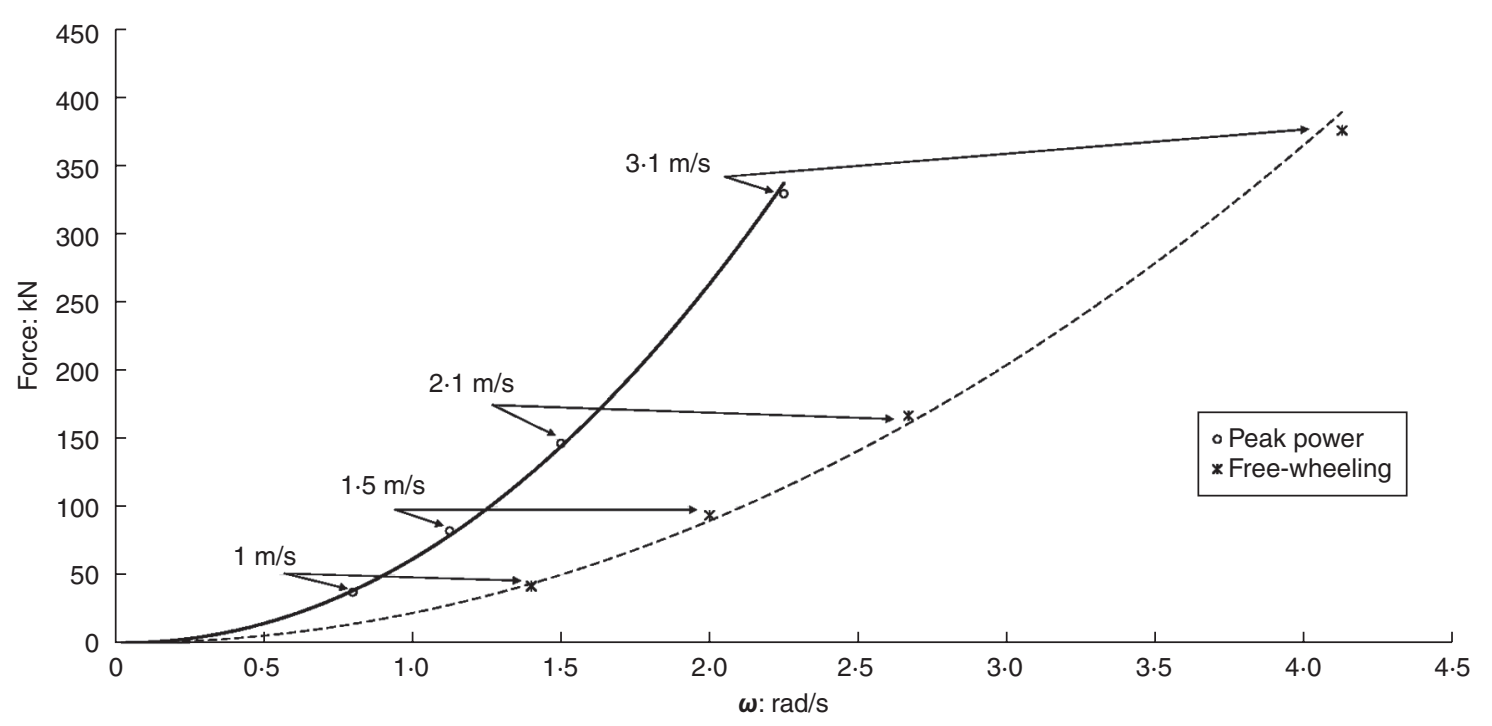

Figure 12. Resultant sliding force on a single turbine for increasing angular velocity

\begin{tabular}{|lc|}
\hline & $\begin{array}{c}\text { Maximum axial } \\
\text { loading: } \mathrm{kN}\end{array}$ \\
\hline Single turbine & 380 \\
Single turbine + stanchion & 640 \\
Frame only & 1530 \\
Five turbines + stanchions + frame & 4730 \\
\hline Table I. Magnitude of the maximum axial loading as predicted by \\
Fluent
\end{tabular}

reached. As the free-wheeling velocity is reached, the vertical force tends to zero. If, for simplicity, it is assumed that all the turbines approach the free-wheeling velocity at the same time, the axial force on the structure becomes a maximum at approximately $4730 \mathrm{kN}$, as shown in Table 1 . If a safety factor of 2 is assumed then the maximum sliding force is $\sim 9500 \mathrm{kN}$. The downward-acting force will be due to the mass of the structure only, since $\boldsymbol{F}_{y}$ from Equation 9 tends to zero. Hence, applying Equation 9 and assuming the mass of the structure to be $2200 \mathrm{t}(22000 \mathrm{kN})$, the frame will not slide providing the coefficient of friction is greater than or equal to $0 \cdot 43$.

\section{DISCUSSION}

When a flow passes around a turbine array, the fluid velocity increases by approximately $10-15 \%$. This could be used to advantage in the placing of multiple turbine arrays. For the modelled turbine array, turbines 1 and 2 extract the most power for both frame apex tail and head into the flow.

The force on the frame is highest when the frame apex is head into the flow. For the turbines used in this study, which have been shown to have a predicted power coefficient of $\sim 0 \cdot 40$, and using a safety factor of 2 , the frame will not slide providing the coefficient of friction is not less than $0 \cdot 43$. The implication then, given the assumptions made and that the coefficient of friction between, say, steel and concrete is also around $0 \cdot 43$, is that the frame would have to be either anchored or piled/pinned into position or the downward force of the frame increased via ballast or hydrodynamic loading. Clearly the risk of sliding will decrease with a lower tidal flow rate but if the turbine blades were to be redesigned and the efficiency increased, then the peak sliding force will also increase. Depending on the nature of the bed on which the frame rests, the pressure exerted by the base of the three stanchions may help the frame to sink slightly, which could help secure the structure. If the surface is bedrock, however, the frame may simply sit directly on top of the surface and sliding may be more likely to occur.

This study highlights several recommendations for an improved design.

(a) In the current design, there may be the possibility of a vibration problem due to interference between the wakes and the bracing when the frame apex is head into the flow. An alternative solution for lowering the structure might thus be desirable. Another solution might be to use a more slender support at the rear of the turbine to reduce the size of the wake.

(b) A more slender support at the back of the turbine would allow more fluid to pass through the turbine and hence increase overall efficiency.

(c) The position and geometry of the generator housing can cause a significant wake, and would be better located on the mainland where access for maintenance would be easier, less expensive and may also reduce the total force acting on the structure.

(d) The drag force on the structure may be reduced by using more streamlined members. However, as the tide turns, the force on the frame could become much higher than if cylindrical sections were used. Hydrofoils may be an alternative to increase the force acting down and hence prevent sliding. This requires more investigation.

Further work is required to investigate any oscillatory behaviour of the individual wakes from each turbine. Clearly, validation of an actual turbine array of the scale studied would be preferable, but not practical. A study of a scale model in a water flume would be ideal for validation of the CFD model prior to scaling. 


\section{CONCLUSIONS}

A free-standing five-turbine array has been studied in a $3.09 \mathrm{~m} / \mathrm{s}$ (6 knot) tidal flow using CFD. The work has highlighted the following issues.

(a) Fluid velocity fluid increases around the structure; this may be used to advantage in positioning multiple turbine arrays.

(b) The power extracted from the array is highest when the frame apex is tail into the flow.

(c) Several improvements to the design could be implemented.

(d) Given the considerable loading applied to the structure, significant seabed attachment is required if the problem with the coefficient of friction is to be overcome.

\section{REFERENCES}

1. Black and Veatch. Tidal Stream Energy Resource and Technology Summary Report. The Carbon Trust, London, 2005.

2. Department for Trade and Industry. SEAFLOW Marine Current Turbines Project Summary. DTI, London, 2006, report PS244.

3. DEPARTMENT FOR TRADE AND IndUSTRY. Final Report on Preliminary Works Associated with 1 MW Tidal Turbine. DTI, London, 2006, Project reference T/06/00233/00/00. URN 06/2046.

4. See http://www.seageneration.co.uk/seagen-installation.asp

5. See http://www.marineturbines.com/18/projects/20/ the_skerries/

6. FujtTA Research. Wave and Tidal Power. 2000. See www.fujitaresearch.com/reports/tidalpower.html for further details. Accessed 03/03/2009.
7. SoAres C. Tidal Power: The Next Wave of Electricity, 2002. See www.pollutionengineering.com for further details. Accessed 03/03/2009.

8. The Carbon Trust. United Kingdom Wave and Tidal Energy Study. Variability of UK Marine Resources. Carbon Trust, London, 2005, Final report.

9. Egarr D. A., O’Doherty T., Morris S. and Ayre R. G. Feasibility study using computational fluid dynamics for the use of a turbine for extracting energy from the tide. Proceedings of the 15th Australasian Fluid Mechanics Conference, Sydney (BeHnia M., Lin W. and McBain G. D. (eds)). 2004, CD-ROM.

10. BeTZ A. Introduction to the Theory of Flow Mechanics (RAndall D. G. (Trans.)). Pergamon Press, Oxford, 1966.

11. White F. M. Fluid Mechanics, 3rd edn. McGraw-Hill, New York, 1979.

12. Mason-Jones A., O'Doherty T., O'Doherty D. M., Evans P. and WooldriDge C. F. Characterisation of a HATT using CFD and ADCP site data. Proceedings of World Renewable Energy Congress (WREC), Glasgow (SAYIGH A. (ed.)). 2008, pp. 941-946.

13. Mason-Jones A., Evans P., Wooldridge C. F., O’Doherty D. M., O'DoherTY T. and FRYETT I. The use of ADCP data from the Inner Bristol Channel, UK and CFD to study power attenuation effects on HATT performance. Proceedings of the 16th European-Based Biennial Conference of the International Federation of Hydrographic Societies (Hydro 8), Liverpool (ETKINSON H. (ed.)), 2008.

14. Massey B. S. Mechanics of Fluids, 6th edn. Chapman \& Hall, London, 1991.

\section{What do you think?}

To comment on this paper, please email up to 500 words to the editor at journals@ice.org.uk

Proceedings journals rely entirely on contributions sent in by civil engineers and related professionals, academics and students. Papers should be 2000-5000 words long, with adequate illustrations and references. Please visit www.thomastelford.com/journals for author guidelines and further details. 